\title{
An experimental study on the shifting dynamics of the chain CVT
}

\author{
[ Ahmet YILDIZ, Francesco BOTTIGLIONE, Giuseppe CARBONE]
}

\begin{abstract}
This paper is concerned with an experimental analysis of the shifting dynamic behavior of a chain continuously variable transmission (CVT) system. Firstly, the steady-state experiments are carried out for different speed ratio. After that, the transient responses of the CVT, the main interest of this paper, are analyzed in different conditions. The tests are performed for different step changes of the ratio of the drive and driven clamping forces and for different angular velocities of drive side. The results demonstrate that the speed ratio reaches high value for high steps; however this relation is nonlinear. Moreover, it is realized that the characteristic shifting response time of speed ratio decreases as the angular velocity of drive pulley increases until a limiting value is reached.
\end{abstract}

Keywords-CVT, Shifting, Dynamics, Transient, Response

\section{Introduction}

Continuously variable transmission (CVT) systems have been widely used in many different areas as an alternative to conventional speed changers. This is due to the fact that there are some advantages such as smoothness of operations, infinite range of speed ratio, easy drivability and quiet working.

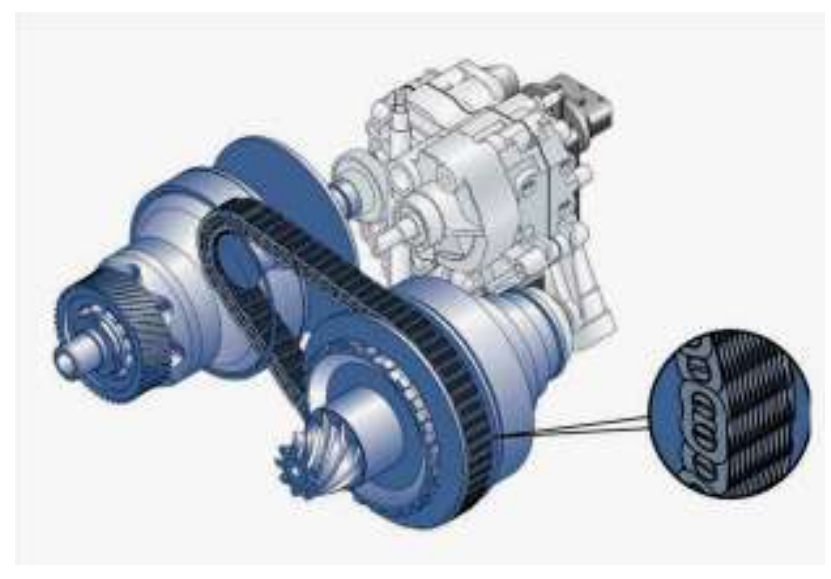

Figure 1. Audi Chain Continuously Variable Transmission

\section{Ahmet YILDIZ ${ }^{1,2}$}

${ }^{1}$ Politecnico Di Bari, Italy

${ }^{2}$ Uludag University, Bursa, Turkey

\section{Francesco BOTTIGLIONE}

Politecnico Di Bari

Italy

\section{Giuseppe CARBONE}

Politecnico Di Bari

Italy
CVT systems have been used increasingly in the automotive industry, since they enable engines to run at optimal speeds, thus providing considerable fuel savings and therefore lower emission values [1,2] or optimized energy consumption in electric vehicles [3], also improving the drive comfort. CVT transmission can be successfully employed in hybrid vehicles as well [4,5]. Moreover, CVT variators are gaining an important interest for large power applications, like [6-10], trucks [11], variable speed machinery for manufactory [12,13]. Authors in [13] propose a new mechanical press concept that equipped with a CVT to obtain more speed variability than the classical ones.

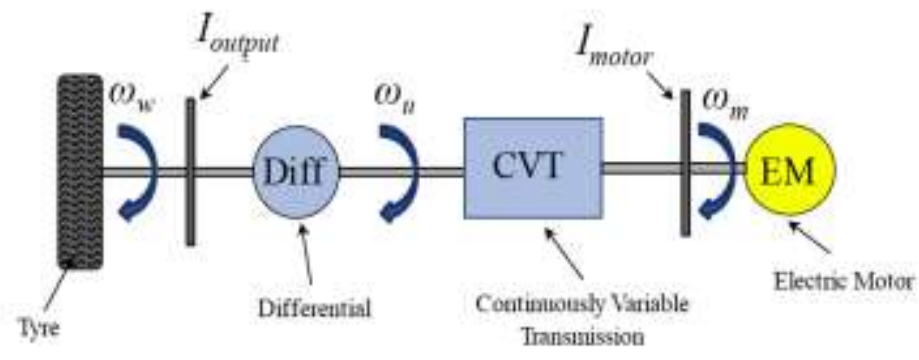

Figure 2. Shematic of battery electric vehicles layout with CVT [3]

There are different types of CVT systems: Toroidal [1415], belt/chain [16,17] as shown in Figure 1, ball [18] and spherical [19]. In this paper, we focus on Gear Chain Industrial (GCI) chain CVT, which has become more common because of its low manufacturing costs and the possibility to be applied for extremely high torque applications.

The control and efficiency are key issues for transmission; therefore a great deal of research has been dedicated to investigate the mechanical behavior of the system. Although there are a lot of researches on CVT system in steady-state conditions, little experimental research has been dedicated on the transient behavior of the variator.

Carbone et al. in [20] developed a theoretical model of belt CVT during rapid ratio speed changes for analyzing the dynamical response of the system during the transient condition. The proposed model can be used to obtain some relations between the axial thrust, torque and tensions on tight and slack side of the belt.

In the next study of Carbone et al. in [21], it is demonstrated that the pulley bending has an important effect on the transient response of the variator. The authors developed a detailed theoretical model which is able to describe the slow shifting maneuvers called "creep mode", behavior and the fast shifting maneuvers called "slipmode" behavior of the variator. It was also shown how the CVT shifting behavior moves toward the limiting case of the rigid pulleys as the rate of change of speed ratio increases. 
In [22], the shifting behavior of variator has been examined at steady state and also in transient conditions but under no load conditions. The experimental investigation was carried out by using the V-belt CVT in order to compare the theoretical predictions of the theoretical model developed in [21].

In this paper the characterization of the transient response of the chain CVT is carried out experimentally. The transient responses of the CVT are examined for different step change of the clamping forces ratio and for different angular speed of motor. Thus, the effects of these parameters on the transient response are determined.

\section{CVT Test Bench}

In this section, the test bench used to perform the measurements on CVT is described. The experimental tests have been carried out on a chain CVT by Gear Chain Industrial B.V. (GCI), mounted on the Power Loop Test Rig in Politecnico Di Bari.

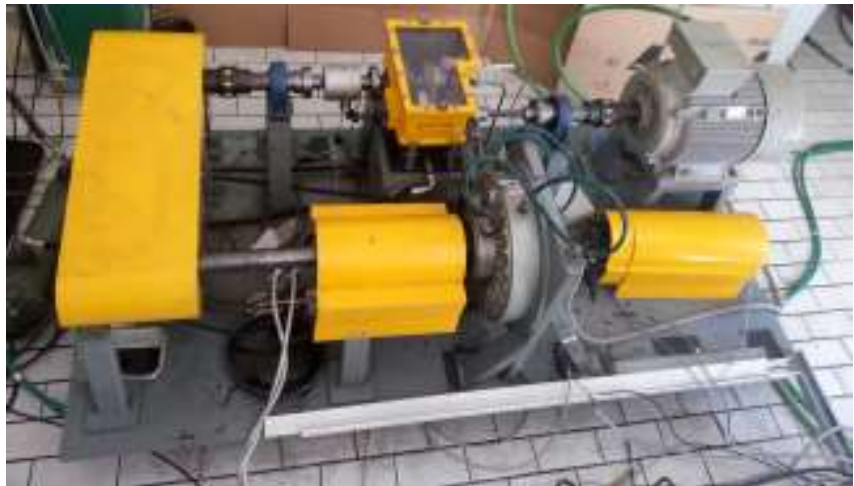

(a)

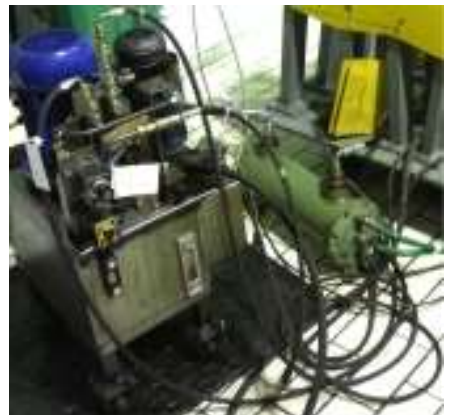

(b)

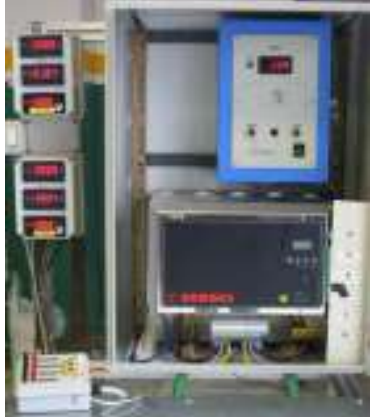

(c)
Figure 3. CVT test bench (a) general view, (b) hydraulic pumps and tank, (c) the control units of motor and brake

The chain CVT used for experiments is characterized by the following data: belt length $L=649.49 \mathrm{~mm}$, belt width $b=24 \mathrm{~mm}$, center-to-center distance of the pulleys $i=155$ $\mathrm{mm}$, undeformed sheave angle $\beta_{0}=11 \mathrm{deg}$. The primary pulley area is $A_{D R}=0.01979 \mathrm{~m}^{2}$ while the secondary pulley area is $A_{D N}=0.009719 \mathrm{~m}^{2}$.

As shown in Figure 3, the power motor of variator is a three-phase asynchronous 4 poles and $30 \mathrm{~kW}$ of power Siemens motor whose angular speed is controlled by the Berges inverter. The resistant torque is obtained by an electromagnetic brake located on a countershaft connected to an output shaft through a synchronous belt transmission. The test rig is equipped with pressure, torque and displacement sensors for the acquisition of main operative parameters.

A Labview program is developed to control the test bench and save the all data such as speed ratio, drive and driven pressure, torque and angular velocity of driven side, as shown in Figure 4.

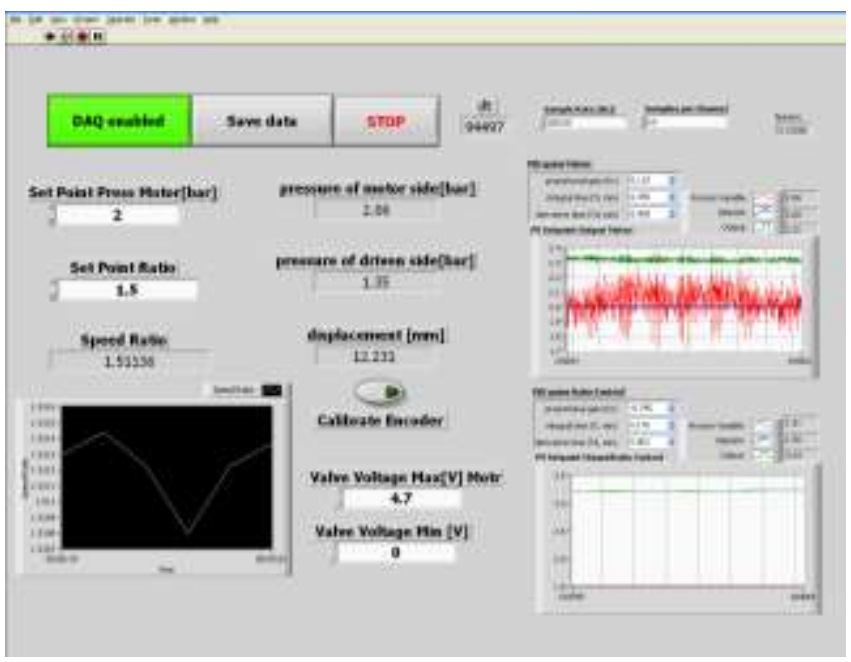

Figure 4. Developed Labview program for controlling the test bench and recording the data's

\section{Experimental Setup}

In order to describe the transient response of variator, a step change of the ratio of clamping forces drive and driven sides $\left(S_{D R} / S_{D N}\right)$ is given starting from steady state conditions. Thus, a step of the oil pressure in drive side $\left(P_{D R}\right)$ is given by controlling the voltage of servo valves.

The clamping force of drive side is calculated as

$$
S_{D R}=P_{D R} A_{D R}+\omega_{D R}^{2} f_{c, D R}
$$

where $\omega_{D R}$ is the angular velocity of drive side. The coefficient $f_{c, D R}$ is

$$
f_{c, D R}=\pi\left(\frac{\rho_{\text {oil }}}{4}\right)\left(r_{D R 1}^{4}-r_{D R 2}^{4}\right)
$$

where $\rho_{\text {oil }}=870 \mathrm{~kg} / \mathrm{m}^{3}$ at $20^{\circ} \mathrm{C}$ and $r_{D R 1}=0.0825 \mathrm{~m}$ and $r_{D R 1}=0.0225 \mathrm{~m}$. The driven clamping force is calculated as

$$
S_{D N}=P_{D N} A_{D N}+\omega_{D N}^{2} f_{c, D N}+F_{\text {spring }}
$$

where $\omega_{D N}$ is the angular velocity of driven side and $F_{\text {spring }}$ is the spring force on driven pulley. The coefficient $f_{c, D N}$ is;

$$
f_{c, D N}=\pi\left(\frac{\rho_{\text {oil }}}{4}\right)\left(2 r_{D N 1}^{2} r_{D N 3}^{2}-r_{D N 2}^{4}-r_{D N 3}^{4}\right)
$$

where the quantities $r_{D N 1}=0.0600 \mathrm{~m}, r_{D N 2}=0.0225 \mathrm{~m}$ and $r_{D N 3}=0.0321 \mathrm{~m}$.

The spring force can be calculated as

$$
F_{\text {spring }}=f_{\text {spring,low }}+2 c_{\text {spring }}\left(r_{D N, \text { low }}-r_{D N}\right) \tan \left(\beta_{0}\right)
$$

where $f_{\text {spring,low }}=536 \mathrm{~N}$, the stiffness of the spring $c_{\text {spring }}=20 \mathrm{~N} / \mathrm{m}$, the pitch radius of driven pulley at minimum speed ratio $r_{D N, \text { low }}=0.0741 \mathrm{~m}$. 
In the experimental tests the speed ratio of variator $\tau$ is determined by measuring the pitch radii. By means of a linear encoder it is possible to determine the axial position a of the moveable pulley sheave shown in Figure 5. The pitch radius $R_{D R}$ of the drive pulley is used to evaluate the geometric speed ratio thanks to following equation:

$$
L=\pi \rho \frac{1+\tau}{\tau}+2 \rho \frac{1-\tau}{\tau} \arcsin \left(\rho \frac{1-\tau}{\tau}\right)+2 \sqrt{1-\left(\rho \frac{1-\tau}{\tau}\right)^{2}}
$$

where the quantity $\rho=R_{D R} / i$.

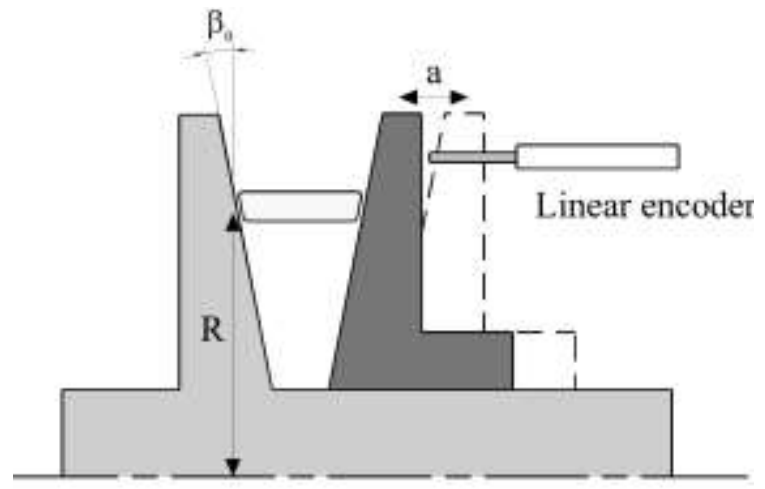

Figure 5. Representation of the measurement of the pitch radius of drive pulley by a linear encoder

The following equation is used to calculate the $R_{D N}$

$$
R_{D N}=R_{D N, \max }-\frac{a}{2 \tan \beta_{0}}
$$

where the $R_{D N \text {, max }}=0.0741 \mathrm{~m}$.

The traction coefficient of driven side $\mu_{D N}$ is

$$
\mu_{D N}=\frac{\cos \beta_{0}}{2} \frac{T_{D N}}{R_{D N} S_{D N}}
$$

where $T_{D N}$ and $R_{D N}$ are the torque load and the pith radii of the pulley in driven side.

\section{Experimental Results}

In this section, the experimental results are presented in both the case of steady-state and the transient conditions. However, the main intent of this study is the shifting dynamics of the variator since these analyses are very important to control the speed ratio

\section{a. Steady State Experiments}

In steady state experiments, the initial condition of the transient analyses is determined. In other words, the clamping forces ratios for a certain torque load and speed ratio is investigated.

Figure 6 shows that the ratio of clamping forces increases as the traction coefficient increases almost linearly. Similarly, it shows that the higher speed ratio the higher the clamping forces ratio. In this case, the input angular velocity, the clamping forces of driven side and the torque load on the driven shaft are fixed as $500 \mathrm{RPM}, 20 \mathrm{kN}$ and $20 \mathrm{Nm}$ respectively.

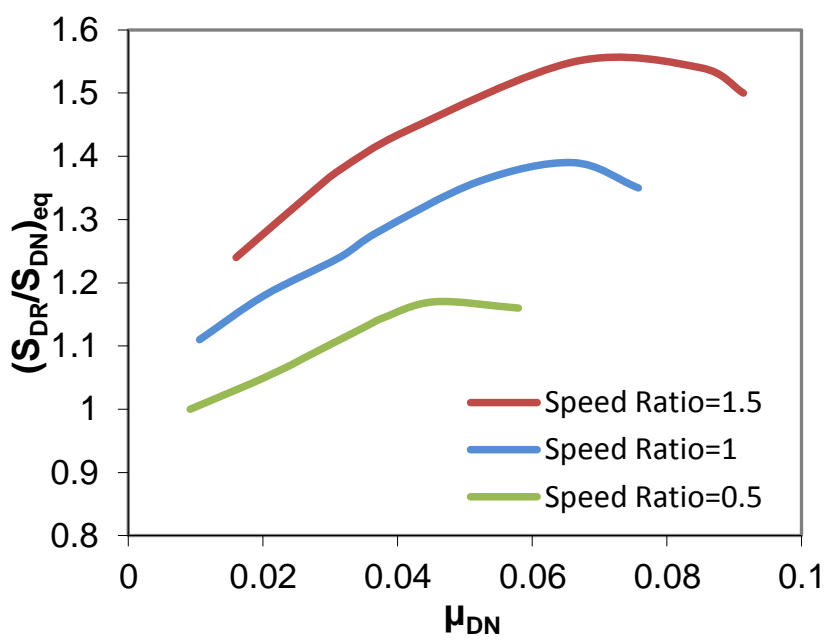

Figure 6. The ratio of clamping forces as a function of traction coefficient for different speed ratio at $\omega_{D N}=500 R P M, S_{D N}=20 \mathrm{kN}$ and $T_{D N}=20 \mathrm{Nm}$.

\section{b. Transient Experiments}

In order to investigate the time response, a step of the ratio of clamping forces at steady state is given in drive side pressure. Figure 7 demonstrates that the transient response of the chain variator for the different step of the ratio of the clamping forces at steady state condition. In this case, the input angular velocity, the clamping forces of driven side and the torque load on the driven shaft are fixed for the initial condition as $500 \mathrm{RPM}, 20 \mathrm{kN}$ and $20 \mathrm{Nm}$ respectively. After that, a step of ratio of clamping forces $\left(\mathrm{S}_{\mathrm{DR}} / \mathrm{S}_{\mathrm{DN}}\right)$ is given. This strategy is followed for three different steps.

It is realized that the speed ratio increases up to new steady state conditions like a first order dynamic system. It can be easily seen from the figure that this increase has a nonlinear relation with the step value.

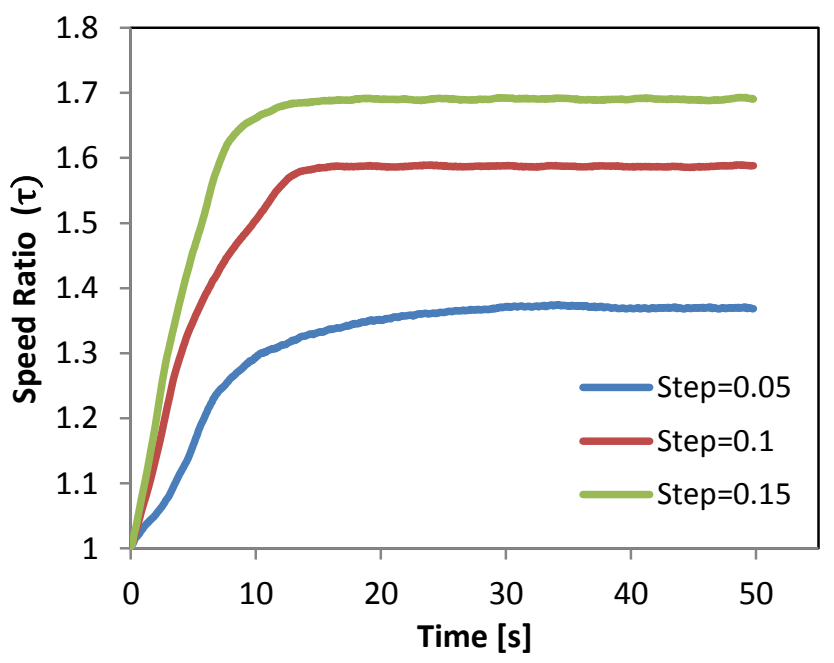

Figure 7. The transient response of the chain CVT for the different step of the ratio of clamping forces $\left(S_{D R} / S_{D N}\right)$ at steady state conditions with $\omega_{D N}=500 \mathrm{RPM}, S_{D N}=20 \mathrm{kN}$ and $T_{D N}=20 \mathrm{Nm}$ 


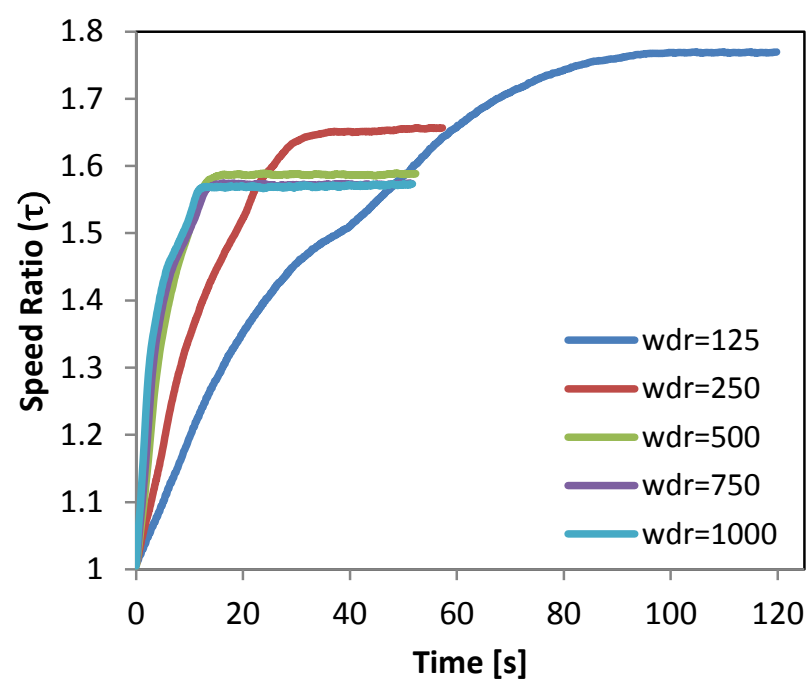

Figure 8. The transient response of the chain CVT for the different angular velocity of drive pulley with the same step 0.01 at $S_{D N}=20 \mathrm{kN}$ and $T_{D N}=20 \mathrm{Nm}$.

The Figure 8 indicates the time response of speed ratio of the CVT for the different angular velocity of the drive pulley. In these experiments the clamping forces of driven side and the torque load on the driven shaft are fixed for the initial condition as $20 \mathrm{kN}$ and $20 \mathrm{Nm}$ respectively. It is given a same step 0.1 of the ratio of ratio of claping forces (SDR/SDN). This strategy is followed for three different angular velocity of driven pulley.

It is analyzed that increasing the angular velocity of drive pulley decreases the response time of CVT and the new stationary value of the speed ratio also decreases. However, this happens up to $\omega_{D R}=500 \mathrm{RPM}$, and after this value increasing the angular velocity of drive pulley does not affect the transient response of the system in terms of both response time and the value of speed ratio. The reason is the lubrication phenomena: increasing the angular velocity increases the lubricant film thickness and thus reducing the friction coefficient. Therefore one can expect that when the angular velocity is increased beyond a certain value, then film thickness proportionally increases and the the friction coefficient proportionally decreases. Since the time response depends also on the friction coefficient the two phenomena (higher velocity and smaller friction) balance each other so no effect on the response is observed.

\section{v. Conclusion}

In this study the transient response of the chain CVT is investigated experimentally. In the steady-state conditions the ratio of clamping forces as a function of the traction coefficient is determined. After that the time response of the speed ratio is analyzed for the different steps of the ratio of clamping forces and for the different values of angular velocity of drive pulley. Results show that the ratio of clamping forces increases when either the speed ratio or the traction coefficient increases. It is also realized that the speed ratio reaches higher steady-state values for higher steps. Moreover, the response time of the speed ratio decreases as the angular velocity of drive pulley increases. However, beyond a certain value of the angular velocity the response time is no longer affected by the angular velocity of the pulleys.

\section{Acknowledgment}

Ahmet YILDIZ would like to thank the Scientific and Technological Research Council of Turkey (TUBITAK) for supporting him one year in Italy as a scholar during his $\mathrm{PhD}$ thesis.

\section{References}

[1] Brace C., Deacon M., Vaughan N. D., Burrows C. R., Horrocks R. W., 1997, Integrated passenger car diesel CVT powertrain control for economy and low emissions, ImechE International Seminar S540, Advanced Vehicle Transmission and Powertrain Management, September 25-26, 1997.

[2] Brace C., Deacon M., Vaughan N. D., Horrocks R. W., Burrows C. R., 1999, The Compromise in Reducing Exhaust Emissions and Fuel Consumption from a Diesel CVT Powertrain over Typical Usage Cycles, Proc. CVT'99 Congress, Eindhoven, The Netherlands, pp. 27 33.

[3] Bottiglione, F., De Pinto, S., Mantriota, G., Sorniotti, A. Energy Consumption of a Battery Electric Vehicle with Infinitely Variable Transmission, Energies 7(12) 8317-8337 (2014)

[4] Bottiglione, F., Carbone, G., De Novellis, L., Mangialardi, L., Mantriota, G., Mechanical hybrid KERS based on toroidal traction drives: an example of smart tribological design to improve terrestrial vehicle performance, 2013, 918387, Advances in Tribology (2013)

[5] Bottiglione, F., Contursi, T., Gentile, A., Mantriota, G., The Fuel Economy of Hybrid Buses: The Role of Ancillaries in Real Urban Driving, Energies 7(7), 4202-4220 (2014)

[6] Mangialardi L., Mantriota G., The Advantages of Using Continuously Variable Transmission in Wind Power Systems, Renewable Energy, 2(3), pp. 201-209 (1992)

[7] Mangialardi L., Mantriota G., Automatically Regulated C.V.T in Wind Power Systems, Renewable Energy, 4(3), pp. 299-310 (1994)

[8] Mangialardi, L., Mantriota, G., Continuously Variable Transmission With Torque-Sensing Regulators in Waterpumping Windmills, Renewable Energy, 4(7), pp. 807-823 (1994)

[9] Mangialardi L., Mantriota G., Dynamic Behaviour of Wind Power Systems Equipped With Automatically Regulated Continuously Variable Transmission, Renewable Energy, 7(2), pp. 185-203 (1996)

[10] Idan M., Lior D., Continuous Variable Speed Wind Turbine Transmission Concept and Robust Control, Wind Eng., 24(3), pp. 151-167 (2000)

[11] Brown A.W., van Rooij J., Frank A.A., The Design of an Inline GCI Chain CVT For Large Vehicles, International Continuously Variable and Hybrid Transmission Congress, UC Davis, Paper No. 54 (2004)

[12] Yildiz A., Kopmaz O., Dynamic analysis of a mechanical press equipped with a half-toroidal continuously variable transmission, International Journal of Materials and Product Technology, 50(1), pp.22-36 (2015)

[13] Yildiz A., Kopmaz O., Telli C. S., Dynamic modeling and analysis of a four-bar mechanism coupled with a CVT for obtaining variable input speeds, Journal of Mechanical Science and Technology, 29(3), pp.1001-1006 (2015)

[14] Carbone, G., Mangialardi, L. and Mantriota, G. A comparison of the performances of full and half toroidal traction drives, Mechanism and Machine Theory, 39( 9), pp.921-942 (2004)

[15] Zhang, Y., Zhang, X. and Tobler, W. A systematic model for the analysis of contact, side slip and traction of toroidal drives, Journal of Mechanical Design ASME, 122( 4), pp.523-528, (2000)

[16] De Novellis L., Carbone G., Experimental investigation of chain link forces in continuously variable transmissions, ASME Journal of Mechanical Design, doi: 10.1115/1.4002764, (2010).

[17] Srivastava, N. and Haque, I. A review on belt and chain continuously variable transmissions (CVT): dynamics and control, Mechanism and Machine Theory, 44(1), pp.19-41, (2009) 
[18] N. P. Belfiore and G. D. Stefani, Ball toroidal CVT: a feasibility study based on topology, kinematics, statics and lubrication, International Journal of Vehicle Design, 23 (3-4), pp.304-331, (2003)

[19] Kim, J., Park, F.C., Park, Y. and Shizuo, M. Design and analysis of a spherical continuously variable transmission, Journal of Mechanical Design ASME, 124(1), pp.21-29, (2002)

[20] Carbone, G., Mangialardi, L. and Mantriota, G., Theoretical model of metal V-Belt drives during rapid ratio changing, Journal of Mechanical Design, 123 (1), 111-117, (2001).

[21] Carbone G., Mangialardi L., Mantriota G., The influence of pulley deformations on the shifting mechanisms of MVB-CVT, ASME Journal of Mechanical Design, 127, 103-113 (2005).

[22] Carbone G., Mangialardi L., Bonsen B., Tursi C., Veenhuizen P.A., CVT dynamics: theory and experiments, Mechanism and Machine Theory, 42(4), pp. 409-428. (2007)

[23] Carbone G., De Novellis L., Commissaris G., Steinbuch M., An Enhanced CMM model for the prediction of steady state performance in CVT chain drives, ASME Journal of Mechanical Design, 132(2), 1$8(2010)$

About Author (s):

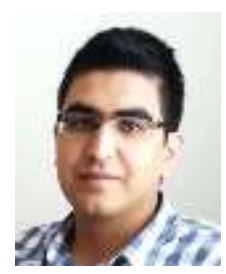

Ahmet YILDIZ is a research assistant in Uludag University, Bursa-Turkey. $\mathrm{He}$ is currently a visiting researcher for his Ph.D. thesis in the Mechanical Engineering Department of Politecnico di Bari, Italy. His research area includes the dynamics of the mechanisms, machine theory and vibration systems.

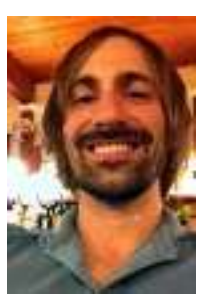

Francesco Bottiglione is Assistant Professor of Applied Mechanics at Polytechnic of Bari - Italy. He has been visiting researcher at University of Surrey, UK. His research activity is in the area of automotive engineering and tribology. He has published more than 40 publications of which 20 on indexed journals.

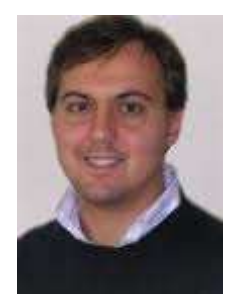

Giuseppe Carbone is Associate Professor of Applied Mechanics at Polytechnic of Bari - Italy. He has been visiting scientist at the Eindhoven University of Technology and Research Fellow at the Forschungszentrum-Juelich, Institute of Solid State Research. He has been also visiting scientist at Imperial College London, UK. His main area of research focuses on tribology, biomimetics, continuously variable transmissions. He has published more than 190 publications of which 75 on ISI iournals. 